\title{
Effect and influencing factors of modified biochar adsorption for the removal of nitrate nitrogen from water bodies
}

\author{
Yang hui, yan yujie, zhang jiaqi \\ ${ }^{1}$. shenyang jianzhu university municipal and environmental engineering college, shenyang liaoning, 110168;
}

\begin{abstract}
Nitrate-nitrogen pollution in water is a global problem. The research on the remediation technology of $\mathrm{NO}^{-}-\mathrm{N}$ polluted water has become a hot research direction in recent years. Biochar has a good adsorption effect on nitrate nitrogen because of its unique surface structure and rich surface properties. In this paper, the basic properties of biochar are introduced, and the research progress on the adsorption effect of modified biochar for nitrate nitrogen removal and the influencing factors are summarized. The problems and shortcomings in the current technology field were analyzed, and the research prospect and direction of using biochar to remove nitrate nitrogen were pointed out.
\end{abstract}

\section{Introduction}

With the rapid development of society and economy, more and more attention has been paid to the problem of nitrate pollution in water source in recent years. In the past few decades, the concentration of nitrate nitrogen in groundwater has increased rapidly in many areas of China, which is mainly due to the excessive application of nitrogen fertilizer in agricultural cultivation. Studies have pointed out that only less than $40 \%$ of the excessive nitrogen fertilizer used in agriculture is used by plants, and most of it enters the water environment through various ways. In particular, the loss of nitrogen fertilizer caused by runoff and leaching from farmland leads to excessive nitrate nitrogen content in many groundwater and surface water. Studies have pointed out that only less than $40 \%$ of the excessive nitrogen fertilizer used in agriculture is used by plants, and most of it enters the water environment through various ways. In particular, the loss of nitrogen fertilizer caused by runoff and leaching from farmland leads to excessive nitrate nitrogen content in many groundwater and surface water.

High concentration of nitrate nitrogen will cause carcinogenesis, infant methemoglobin, resistance to thyroid hormone and other adverse effects on human health, but also cause eutrophication of water, acute poisoning of animals and plants, diseases and insect pests and other hazards. At present, there are three methods to remove nitrate nitrogen in water body: physical-chemical method, chemical method and biological method. The use of biochar for nitrate nitrogen adsorption and removal has caused good environmental effects and has been widely paid attention to and become a research hotspot of water treatment. Biochar is a carbon-rich solid substance produced by pyrolysis of biomass under high temperature, anoxic or anaerobic conditions. It has a large specific surface area and porosity, a large number of high density negative charge on the surface, hydroxyl $(-\mathrm{OH})$, ketone group $(-\mathrm{C}=\mathrm{O})$ and other oxygen-containing active functional groups, is a new type of cheap adsorbent. Studies have shown that the adsorption capacity of biochar for nitrate nitrogen is weak due to the negative charge on the surface, so modification methods are usually used to enhance its adsorption capacity. In this paper, some domestic research status of using modified biochar as adsorbent to remove nitrate nitrogen from water was summarized and analyzed, hoping to provide reference for the research and application of biochar as water treatment materials in China.

\section{Adsorption mechanism of modified biochar to remove nitrate nitrogen}

Experts and scholars at home and abroad have made important progress in the study of the adsorption mechanism of modified biochar for nitrate nitrogen removal. They generally believe that the types of biochar and the different modification methods have different effects on the adsorption and effect of nitrate nitrogen, and different adsorption mechanisms will be formed with different reaction conditions. The adsorption mechanism of modified biochar for nitrate nitrogen mainly includes electrostatic adsorption, physical adsorption, ion exchange and adsorption catalytic redox.

\subsection{Electrostatic adsorption}

Electrostatic adsorption refers to the electrostatic interaction between the surface positive charge of modified biochar and nitrate ions. In the study on the adsorption of nitrate nitrogen by modified granular 
biochar, M. A. Khan et al. believed that because the surface of the activated carbon coat after sulfuric acid would load hydrogen ions, the electrostatic adsorption interaction on anions would be enhanced under the action of protonation.

\subsection{Physical adsorption}

Physical adsorption refers to the adsorption of nitrate nitrogen on the surface of modified biochar by intermolecular force. The adsorption capacity is closely related to the specific surface area and porosity of modified biochar. Ming Zhang et al. studied the adsorption properties of $\mathrm{MgO}$-biochar composites prepared in the laboratory on anions $\left(\mathrm{PO}_{4}{ }^{3-}\right.$ and $\left.\mathrm{NO}_{3}{ }^{-}\right)$ and found that the modified biochar composites would form nanoscale microporous structures, which greatly improved the porosity and specific surface area, thus further enhancing the physical adsorption capacity.

\section{3 lon exchange}

Ion exchange is the exchange of ions in a solution with ions in an ion exchanger. D. W. Chho et al. found in the experiment of adsorption of nitrate nitrogen by modified activated carbon that modified granular activated carbon (supported by cationic polymers) increased the ion exchange capacity. When the $\mathrm{pH}$ range is $3 \sim 6$, the adsorption equivalent of electrostatic adsorption decreases with the increase of $\mathrm{pH}$ value. When the $\mathrm{pH}$ value is greater than 6 , with the increase of $\mathrm{pH}$ value, the concentration of negative charge increases, the electrostatic adsorption is weakened, and ion exchange is the main adsorption mechanism.

\subsection{Catalytic redox}

Catalytic redox refers to the adsorption of nitrate nitrogen by surface modified biochares loaded with metal nanoparticles and the promotion of denitrification to produce $\mathrm{N} 2$ and NH4+. When Min-Kyuji et al used activated carbon supported nano-zero-valent iron composite system to remove NO3-, they found that the modified activated carbon could promote the denitrification reaction and produce $\mathrm{N} 2$ and $\mathrm{NH} 4+$, so as to achieve the purpose of removing nitrate nitrogen.

\section{Study on the adsorption effect of modified biochar for nitrate nitrogen removal}

Due to the negative charge on the surface of biochar, its cation exchange capacity is higher than the anion exchange capacity, resulting in a very low adsorption capacity for nitrate. Modification is a commonly used method to improve its adsorption capacity for nitrate nitrogen. Usually, the modification methods of carbon include metal ion modification and acid modification.

\subsection{Metal-modified biochar}

Metal ion loading is one of the common methods of biochar modification. The surface of biochar is mostly negatively charged, and loading metal ions can change its surface electrical properties. At present, the common use of iron, manganese, magnesium, aluminum plasma modification of biomass carbon.

\section{1. 1 Fe modified biochar}

Li Li et al. (2015) treated wheat straw biochar (XBC) and peanut shell biochar (HBC) with iron modification. When the mass ratio of iron to carbon was $1.0,0.4 \mathrm{~g}$ of modified biochar was added to the nitrate solution of $10 \mathrm{mg} / \mathrm{L}$, respectively. The results showed that the adsorption capacity of modified wheat straw biochar for nitrate nitrogen was $591.00 \pm 33.71 \mathrm{mg} / \mathrm{kg}$, which was 15 . 97 times higher than that of unmodified biochar of 32 . $50 \pm 1$. $80 \mathrm{mg} / \mathrm{kg}$. The adsorption capacity of modified peanut shell biochar for nitrate nitrogen was 1182 . $93 \pm 1$. $74 \mathrm{mg} / \mathrm{kg}$, which was 17.18 times higher than the adsorption capacity of $66.47 \pm 3.48 \mathrm{mg} / \mathrm{kg}$ without modification. Zhang Wen et al. (2018) prepared biochar from cattails and reeds and treated it with iron modification. Through the adsorption experiments of two kinds of biochar on nitrate nitrogen, it is concluded that the adsorption capacity of modified biochar on nitrate nitrogen in water is twice that of unmodified biochar.

\section{1. 2 Mg modified biochar}

Using oak sawdust as the carbon base, Zhang et al. modified biochar with $\mathrm{MgCl}_{2}$, and found that $\mathrm{Mg}$ element was loaded on the surface of biochar in the form of $\mathrm{MgO}$, and the adsorption capacity of magnesium modified biochar for NO3--N could reach $21.45 \mathrm{Mg} / \mathrm{g}$.

\section{1. 3 Al modified biochar}

Yin et al. prepared poplar wood chip biochar and modified it with $\mathrm{AlCl}_{3}$, and found that $\mathrm{Al}$ was highly dispersed on the surface of biochar in the form of $\mathrm{AlOOH}$. When the $\mathrm{Al} / \mathrm{C}$ mass ratio was $15 \%$, the adsorption capacity of aluminum-modified biochar for NO3--N was the largest, which was $20.49 \mathrm{mg} / \mathrm{g}$.

\subsubsection{Mn modified biochar}

Zhi Yancai et al. (2015) prepared biochar from peanut shell and modified it with metal loading with $\mathrm{FeCl}$, $\mathrm{MnCl} 2$ and $\mathrm{MgCl} 2$, respectively. The results of batch adsorption experiments showed that the specific surface area of peanut shell biochar modified with iron, manganese and magnesium ions increased by 6.67-12.16 times, and the adsorption capacity of nitrate nitrogen (NO3--N) was significantly enhanced. The maximum adsorption capacity of NO3--N was 41.58, 39.04 and $39.58 \mathrm{mg} \cdot \mathrm{g}-1$, respectively. The effect of iron ion modification was the best. 


\subsubsection{Ca modified biochar}

Xu Hong chao (2017) modified straw biochar, pickled it and adjusted its $\mathrm{pH}$ value to neutral, then weighed $10 \mathrm{~g}$ and added it to $175 \mathrm{~mL} 1 \mathrm{~mol} / \mathrm{L} \mathrm{CaCl} 2$ solution to prepare modified biochar with mass ratio of 0.7 . The adsorption test on secondary effluent showed that the maximum adsorption capacity of $\mathrm{CaCl}_{2}$-modified biochar for $\mathrm{NO}_{3}{ }^{-}-\mathrm{N}$ was $1.633 \mathrm{mg} / \mathrm{g}$.

\subsection{Acid modified biochar}

Acid modification mainly uses strong acids such as hydrochloric acid and sulfuric acid as activators to treat biochar, and enhances the adsorption capacity of biochar by activating biochar to change its pore structure, elemental composition or surface functional group properties.

Wang Bo et al. (2017) prepared biochar from aquatic withered plants Phragmites australis and cattail and modified it with hydrochloric acid. The results of adsorption isotherm showed that the maximum adsorption capacities of modified Phragmatic Reed (MRB) and modified Cattail (MCB) for nitrate nitrogen were $4.6661 \mathrm{mg} / \mathrm{g}$ and $5.5559 \mathrm{mg} / \mathrm{g}$, respectively.

To sum up, the modification of biochar is an effective method to improve its adsorption capacity. Different modification methods can optimize the adsorption performance of biochar to different degrees, and different modification methods have different effects on biochar. Therefore, when preparing modified biochar, different modification methods can be combined to prepare modified biochar with stronger adsorption performance.

\section{Factors influencing the removal of nitrate nitrogen by adsorption of modified biochar}

\subsection{The influence of $\mathrm{pH}$ value}

The experimental results of Zhang Wen et al. (2018) pointed out that with the increase of $\mathrm{pH}$ value of the solution, the negative charge on the surface of the modified biochar increased while the positive charge decreased, leading to the gradual decrease of the adsorption capacity of the modified biochar for nitrate nitrogen, which indicated that the acidic environment was conducive to the removal of nitrate nitrogen by $\mathrm{FeCl}_{3}$ modified biochar.

\subsection{Influence of pyrolysis temperature}

Wu Lijun et al. (2016) prepared corn straw and corn cob biochar by pyrolysis at $400^{\circ} \mathrm{C}$ and $600^{\circ} \mathrm{C}$ respectively. Through the nitrate nitrogen adsorption test, they pointed out that the $\mathrm{pH}$ value of biochar prepared at $600^{\circ} \mathrm{C}$ was higher than that of biochar prepared at $400^{\circ} \mathrm{C}$, and the number of basic oxygen-containing functional groups was more, while the number of acidic oxygen-containing functional groups was less. And the adsorption effect of nitrate nitrogen is lower than that of biochar prepared at $400^{\circ} \mathrm{C}$.

\subsection{The influence of coexisting ions}

$\mathrm{Li} \mathrm{Li}$ et al. (2015) studied the effects of chloride, phosphate and bicarbonate on the adsorption of nitrate nitrogen by modified biochar by adding $0.01 \mathrm{~mol} \cdot \mathrm{L}^{-1}$ $\mathrm{NaCl}, \mathrm{KH}_{2} \mathrm{PO}_{4}$ and $\mathrm{NaHCO}_{3}$ to the prepared nitrate solution, and the results showed that bicarbonate had the largest impact, while phosphate had the smallest impact. The decrease of nitrate nitrogen adsorption by biochar may be caused by the competition between coexisting anions (such as $\mathrm{Cl}^{-}, \mathrm{PO}_{4}{ }^{3-}$, and $\mathrm{HCO}_{3}^{-}$) and nitrate ions or by the blocking of adsorption sites on the surface of modified biochar.

\subsection{The influence of adsorption time}

Maryam, A. T et al. found in the experimental study that the adsorption and removal rate of nitric acid ions by modified powdered activated carbon would change in different stages as time went on.

\subsection{The influence of initial nitrate concentration}

Yuwang et al. found in the experiment that, with the increase of initial concentration, the coefficient $\mathrm{k} 2$ of the pseudo-second-order kinetic equation decreased while the coefficient of the diffusion model inside the particle increased. Therefore, a higher initial concentration corresponds to a higher adsorption removal rate. At the same time, the adsorption kinetics analysis data showed that within the equilibrium time of $20 \mathrm{~min}$, with the passage of time, the adsorption removal rate would increase with the increase of concentration.

\section{Conclusion}

(1) At present, the nitrate nitrogen pollution in China's water is serious, and its removal is extremely urgent. Nitrate pollution prevention and control will be a long-term task of water pollution prevention and control in China in the future.

(2) The adsorption mechanism of biochar on $\mathrm{NO}_{3}{ }^{-}$ includes electrostatic adsorption, physical adsorption, ion exchange and adsorption redox.

(3) Modification of biomass carbon with metal ions and acid can significantly improve its adsorption performance for nitrate nitrogen. However, the influence of different modification methods on biochar also varies greatly, and not all modification methods are favorable. Therefore, the reasonable selection of modified materials and modified methods is to enhance the adsorption performance of biochar, and it is also the key research issue of biochar modification.

(4) The adsorption of biochar on nitrate nitrogen is affected by $\mathrm{pH}$ value, coexisting ions, pyrolysis temperature, adsorption time and initial nitrate concentration. 
(5) At present, there are abundant studies on the application of modified biochar in the treatment of water pollution with remarkable effects, but they mainly focus on the simulation of simulated wastewater experiments in the laboratory, while few studies on the treatment of actual polluted water bodies are carried out. In addition, the simulated nitrate nitrogen polluted water sample in the laboratory is quite different from the reality, especially the research on the recovery and treatment of modified biochar after application is very few, which leads to the lack of experience in guiding the practical application. In the future, it is advisable to make an in-depth study on the treatment of actual water bodies in order to lay a foundation for the early solution of water pollution problems.

\section{Acknowledgments}

Thanks to the support of the "13th five-year plan" water research group for this study, the subject of this study (2018ZX07601001), provided the data of this study.I would like to thank the teachers of the school of environment of shenyang jianzhu university for their hard work and the students who helped me with this paper.

\section{References}

1. Wang. L, G. e, C. L, Xue. Y. Y, et al. A review of biochar adsorption for nitrate nitrogen removal from solution [J]. China Rural Water and Hydropower, 1007-2284 (2015) 02-0032-06.

2. Li. L, Chen. X, Wu. D, et al. Journal of Agro-Environment Science, 2015, 34(1):137-143.

3. Wang. B, Ye. C, Li. FY, et al. Study on the adsorption of nitrate nitrogen from aquatic plant biochar [J]. China Environmental Science, 2017, 37 (1) : 116-122

4. Wu. L. J, Wang. Z. X, Zhang. F, et al. Adsorption of inorganic nitrogen from aqueous solution by corn straw and corn cob biochar [J]. China Environmental Science, 2016, 36(1) : 74 81.

5. Hu. Z. X, Shi. M, Sun. J, et al. Adsorption characteristics of nitrate nitrogen from water by modified Phrase biochar [J]. Jiangsu Agricultural Sciences, 2018, 46 (24) : 359-362.

6. Li. S. S, Wang. C. C, He. X. Y, et al. Adsorption of nitrate nitrogen by modified aquatic plant biochar [J]. Journal of Ecology and Rural Environment, 2018, 34 (4):356-362.

7. Wang. R. R, Lai. X, Li. , et al. Journal of Agro-Environment Science, 2016, 35(9): 1727-1734.

8. Zhang. W, Lu X. T, Han. R, et al. Journal of Ecology and Rural Environment, 2018, 34 (3):253-259.

9. Kong. S. F, Yao, X, C, Zhang. J. Y, et al. Research progress on the characteristics and applications of
biochar[J]. Ecology and Environmental Sciences, 2015, 24(4):716-723.

10. Cui. Y. T. Chemical fertilizer and ecological environment protection [M]. Beijing: Chemical Industry Press, 2000.

11. nitrate pollution in drinking water on human health [J]. Groundwater, 2008, 30 (1) : 57-64.

12. Zhu. J. C. Study on nitrate pollution in groundwater [J]. Beijing Geology, 1995, (2) : 20-26.

13. Liu. C, Liu. X. W, Wu. W. C, et al. Effects of biochar and charcoal-based fertilizer on growth and absorption of heavy metals in oilseed [J]. China Environmental Science, 2016, 36 (10) : 3064-3070.

14. Bi. J. J, Peng. C. S, Xu. H. Z, Research progress of nitrate pollution and treatment in groundwater [J]. Groundwater, 1004-1184(2010) 01-0097-06.

15. Zhang. Q. L, Wang. H, Zhang. L. Q, et al. Effects of nitrate nitrogen pollution in drinking water on human health $[\mathrm{J}]$. Groundwater, 1004-1184(2008)01-0057-03.

16. M. A. Khan, Y. T. Ahn, M. Kumar, et al. Adsorption studies for there moval of nitrate uising modified lignite granular activated carbon[J]. Separation Science and Technilogy , 2011, 46:2575-2584.

17. M. Zhang, B. Gao, Y. Yao, et al. Synthesis of porous $\mathrm{MgO}$-bio-charnanocomposites for removal of phosphate and nitrate from aqueous solutions[J]. Chemical Engineering Journal, 2012, 210:26-32.

18. D. W. Cho, C. M. Chon, Y. Kim, et al. Adsorption of nitrate and $\mathrm{Cr}(\mathrm{VI})$ by cationic polymer-modified granuar activated carbon[J]. Chemical Engineering Journal, 2011, 175:298-305.

19. Wang. X. D, et al. Research progress in the preparation and application of porous biomass carbon materials $[\mathrm{J}]$. Functional Materials, 1001-9731(2017)07-07035-06.

20. Hu. F. P, Luo. w. d, et al. Research progress in the removal of pollutants from water by modified biochar [J]. Industrial Water Treatment, 1005-829X(2019)04-0001-04

21. Zheng. X. Q, Wei. A. L, et al. Adsorption characteristics of nitrate in water by Fe-Mn oxide/biochar composite [J]. Environmental Science, 0250-3301 (2018) 03-1220-13

22. Ji. H. Y, Wang. Y. Y, et al. Research progress in the preparation and application of biochar and modified biochar [J]. Journal of Nuclear Agricultural Sciences, 2018, 32 (11) : $2281 \sim 2287$

23. Liu. S. L, Peng. H. J, et al. Removal of nitrogen and phosphorus from water by biochar from aquatic plants [J]. Environmental Science, 0250-3301 (2019) 11-4980-07 